\title{
ULTRASOUND GUIDED HYDROSTATIC REDUCTION OF INTUSSUSCEPTION IN CHILDREN WITH LATE PRESENTATION
}

\author{
Nadim Ullah', Mohammad Irshad ${ }^{2}$, Ihsan Ullah', \\ Muhammad Imran Khan', Mohsin Hayat', Muhammad Hussain ${ }^{2}$
}

\begin{abstract}
OBJECTIVE: To evaluate the successful management of intussusception through ultrasound guided hydrostatic reduction with respect to duration of symptoms in children up to 6 years of age.

METHODS: Retrospective analysis was done for 68 paediatric patients in the age range from 2.5 months to 6 years at Radiology \& Paediatrics departments, Medical Teaching Institution Lady Reading Hospital, Peshawar. Children primarily diagnosed as intussusception, based on ultrasound findings \& managed conservatively with ultrasound guided hydrostatic reduction from January 2014 to December 2017 were included in the study. Their management was analyzed with respect to duration of symptoms. Children who were primarily managed surgically were excluded from study.
\end{abstract}

RESULTS: A total of 68 patients in the age range from 2.5 months to 6 years were included in the study. Male to female ratio was $3.25 / 1$ with 52 males $(\leq 1$ year $=45 \&>$ lyear $=7$ ) and 16 females $(\leq I$ year $=\mid I \&>I$ year $=5$ ). Abdominal pain was reported in all $(100 \%)$ cases, followed by bleeding per rectum in $35.2 \%$ and abdominal mass in $13.2 \%$ cases. Classic triad of abdominal pain, abdominal mass and bleeding per rectum was reported only in $8.8 \%$ of cases. Overall rate of success of hydrostatic reduction was $89.70 \%(n=61 / 68)$. Success rate in cases presented $\leq 48$ hours was $97.56 \%$ and in cases presented $>48$ hours was $77.77 \%(p<0.05)$.

CONCLUSION: Hydrostatic reduction for intussusception in paediatric patients under ultrasound guidance has a good outcome. Success rate for patients presenting presented $\leq 48$ hours was better than patients presenting presented $\geq 48$ hours.

KEY WORDS: Intussusception (MeSH); Hydrostatic reduction (Non-MeSH); lleocecal intussusception (Non-MeSH); Child, Preschool (MeSH); Child $(\mathrm{MeSH})$; Infant $(\mathrm{MeSH})$; Ultrasonography $(\mathrm{MeSH})$.

THIS ARTICLE MAY BE CITED AS: Ullah N, Irshad M, Ullah I, Khan MI, Hayat M, Hussain M. Ultrasound guided hydrostatic reduction of intussusceptions in children with late presentation. Khyber Med Univ J 2019; I (I):37-40. DOI:10.35845/kmuj.2019.18747.

\section{INTRODUCTION}

ntussusception is the introversion of a proximal segment of the bowel into distal segment dragging its vascular supply along with it. If intussusception is not extroverted in time, it can lead to ischaemia of the bowel leading to gangrene.' It is a common cause of intestinal obstruction in infants and patients of paediatric age group. lleocolic intussusception is the most common type in children. ${ }^{2}$ Early diagnosis and management is of paramount importance to prevent bowel ischaemia and perforation, and may have a fatal outcome if not managed in time. ${ }^{3}$

Intussusception is common in children
I Assistant Professor, Department of Radiology, Medical Teaching Institute Lady Reading Hospital, Peshawar, Pakistan.

2 Assistant Professor, Department of Paediatrics, Medical Teaching Institute Lady Reading Hospital, Peshawar, Pakistan.

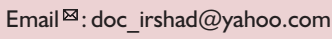
Contact \#: +92-33492448I8.

3 Assistant Professor, Department of Pathology, Institute of Basic Medical Sciences, Khyber Medical University, Peshawar, Pakistan

Date Submitted: October 22, 2018 Date Revised: March 17, 2019 Date Accepted: March 19, 2019

up to 2 years of age but peaks at 4 to 10 months. ${ }^{4-6}$ The cause of intussusception is not identifiable in approximately $90 \%$ cases. Rarely a lead point which is an anatomical abnormality in the intestine acts as the point of initiation of intussusception. The lead point may be a lymph node, intestinal wall edema, Meckel's diverticulum, intestinal lymphoma or any solid lesion of the bowel wall. ${ }^{4,5}$ Low level risk of intussusception was found with the rota virus vaccine after its post license surveillance in rotavirus vaccine (RV), RVI and RV5.

Intussusception may present as abdominal pain, rectal bleeding, abdominal mass, vomiting and diarrhoea. Classically intussusception may present as triad of abdominal pain, abdominal mass and bleeding per rectum in $20-25 \%$ cases only. ${ }^{1,7-9}$ Ultrasonography is the alternative method mainly used for the diagnosis and to identify findings that may direct a therapeutic choice. Other nonsurgical methods recommended are air and barium contrast enema under fluoroscopic guidance. ${ }^{10,11}$

Intussusception is managed nonsurgically by hydrostatic reduction (HR) with fluid, air and contrast enema. Air and contrast enema carry risk of radiation and perforation. Surgical management involves exploratory laparotomy and extroversion of intussusceptum or resection of ischaemic bowel segment. ${ }^{2}$ Prolong duration of symptoms is one of the reasons for primary surgical reduction or bowel resection..$^{9,12}$ Hydrostatic 
TABLE I: CLINICAL PRESENTATION OF INTUSSUSCEPTION

\begin{tabular}{|l|c|c|}
\hline Clinical Feature & Frequency $(\mathbf{n = 6 8 )}$ & Percentage \\
\hline Abdominal Pain & 68 & 100 \\
\hline Per Rectal Bleeding & 24 & 35.2 \\
\hline Abdominal Mass & 09 & 13.2 \\
\hline Vomiting & 08 & 11.7 \\
\hline Diarrhoea & 05 & 7.3 \\
\hline Triade of Pain, Mass and Rectal Bleeding & 06 & 8.8 \\
\hline Onset of Symptoms <24 hours & 23 & 33.82 \\
\hline Onset of Symptoms >24 hours & 45 & 66.17 \\
\hline Cause of Intussusception Found & 05 & 7.36 \\
\hline Idiopathic & 63 & 92.64 \\
\hline
\end{tabular}

TABLE II: DURATION OF SYMPTOMS AND HYDROSTATIC REDUCTION SUCCESS

\begin{tabular}{|c|c|c|c|c|}
\hline \multirow{2}{*}{$\begin{array}{l}\text { Outcome of Hyd- } \\
\text { rostatic Reduction }\end{array}$} & \multicolumn{2}{|c|}{ Duration of symptoms } & \multirow{2}{*}{ Total } & \multirow{2}{*}{$\begin{array}{c}\text { p-value } \\
\text { (Fisher's exact test) }\end{array}$} \\
\hline & $\leq 48$ hours & $>48$ hours & & \\
\hline Successful & $40(97.56 \%)$ & $21(77.77 \%)$ & $61(89.70 \%)$ & \multirow{2}{*}{0.0134} \\
\hline Failed & 이 (2.4\%) & $06(22.22 \%)$ & $07(10.29 \%)$ & \\
\hline Total & 41 & 27 & 68 & \\
\hline
\end{tabular}

reduction of intussusception is more widely method now a days. However, there are limited studies on hydrostatic reduction of intussusception in our region. ${ }^{13,14}$ This study was conducted to evaluate the management of intussusception using ultrasound guided hydrostatic reduction with reference to the duration of symptoms in our setup where late referral to specialized units is a concern regarding management of those conditions where early referral can change the course of treatment.

\section{METHODS}

This retrospective study was conducted at Department of Radiology in collaboration with Department of Paediatrics, Medical Teaching Institute Lady Reading Hospital, Peshawar from January 2014 to December 2017. All children admitted with diagnosis of intussusception were included. Paper record of children who had undergone hydrostatic reduction was accessed after permission of ethical committee of hospital. All cases with complete record were included. Cases with probable diagnosis were excluded. Data of age, gender, presenting symptoms, duration of symptoms, procedure performed and its outcome were recorded.

Children admitted with probable diagnosis of intussusception were admitted to paediatric ward. Abdominal $X$-ray was done to exclude gut perforation. Ultrasound was done to confirm diagnosis. Ultrasound findings of "target sign" on axial scan and "sleeve sign" on longitudinal scan were taken as diagnostic. Other sonographic findings recorded were diameter of intussusceptum, free fluid in abdominal cavity, presence of ischaemia on doppler ultrasound and presence of lead point. Children with septic shock and unstable hemodynamic parameters were directly referred to Paediatric Surgery and were excluded from study.

Intravenous fluids were given. Serum electrolytes were corrected if required. Nasogastric tube was passed to avoid aspiration during procedure as bowel distension can lead to vomiting. Hydrostatic reduction was performed. Children with stable hemodynamic parameters were continuously monitored clinically and with ultrasound. If vital signs were found to be deteriorating or HR failed, children were referred for surgery. Repeat HR was done where indicated.

Children were shifted to ultrasound room. In the presence of parents, child was put in supine position. Foley's catheter of size 22-24 Fr was passed per rectal and balloon was inflated with 40 to $60 \mathrm{ml}$ of normal saline to avoid leak. I.5 litre of normal saline at $37^{\circ} \mathrm{C}$ was connected to Foley's catheter and suspended above couch level to maintain flow under pressure. Child was continuously monitored with ultrasound for retrograde movements of intussusception. Failure of retrograde movements of intussusceptum was considered failure. Maximum of three attempts were done before declaring failure of $H R$ and children were shifted for surgery.

After successful reduction children were given intravenous fluids and antibiotics and kept nil per oral for 24 hours. Pre-procedure, all children received paracetamol and intravenous midazolam for analgesia and sedation respectively.' Data were analysed in Microsoft Excel and presented in tabulated forms.

\section{RESULTS}

Sixty-eight patients were primarily treated with hydrostatic reduction out of which $61(89.7 \%)$ were successfully reduced with HR and seven (10.3\%) failed cases were shifted for surgery. Male to female ratio was $3.25 /$ I with 52 males $(\leq$ I year $=45 \&>$ lyear $=7)$ and 16 females $(\leq 1$ year $=11$ \& $>$ lyear $=$ 5). Mean age was 13.1 months with $I 2.6$ months for male children and 14.8 months for females. Abdominal pain was reported by all cases, followed by bleeding per rectum and abdominal mass. Classic triade of abdominal pain, abdominal mass and bleeding per rectum was reported by a minority of patients as shown in Table I. Majority of children were I year old or younger. One third of the children presented with symptoms for 24 hours or less. Out of delayed presenters 29.41\% presented later than 48 hours. In majority of cases, cause could not be found. Ultrasound confirmed diagnosis in all cases. In minority of cases, causes that were identified were Meckel's diverticulum, mesenteric adenitis and gut gangrene. Nine out of each ten intussusception cases were successfully reduced with hydrostatic reduction. Cases (07/68; 10.29\%), which could not be reduced with hydrostatic reduction were shifted for surgery. 
Majority of those cases shifted for surgery had presented with symptoms for more than 48 hours. Only one death was reported. Success rate of HR with respect to the duration of symptoms was analyzed by Fisher's exact test. At p-value of 0.0134 two tailed, our results were significant as per results in Table II.

\section{DISCUSSION}

In this study on 68 patients, male patients were predominant. Majority presented with abdominal pain, bleeding per rectum and abdominal mass. Overall rate of success of hydrostatic reduction was $89.70 \%$. Success rate in cases presented $\leq 48$ hours was better than cases presented $>48$ hours.

Intussusception is among the common causes of intestinal obstruction in children. In our study $76.5 \%$ patients were males. These findings are consistent with findings of Imran $\mathrm{M}$, et al showing $69.7 \%$ male patients. ${ }^{13}$ Male predominance is recognized and reported per literature. $1,7,8,13$

Almost $90 \%$ of cases are reported to have an unknown cause. ${ }^{15}$ As per our data, in $92.64 \%$ of cases, no lead point was identified. In the rest of cases, a lead point in the form of Meckel's diverticulum, mesenteric adenitis and bowel wall oedema was identified.' Diagnosis is usually delayed because of nonspecific symptoms as presenting feature instead of classic symptoms.' The classic features of intussusception abdominal pain, abdominal mass and bleeding per rectum are reported by minority $(8.8 \%)$ of patients in our study. It commonly presents as abdominal pain, bleeding per rectum, vomiting, abdominal mass and diarrhoea. ${ }^{1,7,12,13,16}$ In the absence of classic symptoms threshold for diagnosis should be kept low in those children presenting with any of the above symptoms alone. High vigilance is particularly required for children below two years of age and diagnosis should be confirmed with ultrasound. $^{16}$

Ultrasound has high sensitivity and specificity for diagnosis of intussusception, reported $100 \%$ in our study. ${ }^{9,13}$ Air and contrast enema has been used for diagnosis and reduction but there is high risk of radiation and perforation. Hydrostatic reduction under ultrasound monitoring is a safe way of reducing intussusception with no risk of radiation.

Overall success rate in our study was $89.70 \%$. Imran $\mathrm{M}$, et al. reported success rate of $81.81 \%$ for non-surgical intervention. ${ }^{13}$ Hasnain MA, et al. had almost similar results, reporting $85.7 \%$ success rate of hydrostatic reduction of intussusception in children. ${ }^{14}$ Some studies have reported that HR is less successful when duration of symptoms is more than 48 hours. Delayed presentation has been reported to have high risk of perforation. ${ }^{17}$ Our study demonstrated success rate of $77.77 \%$ in patients presenting with symptoms for more than 48 hours. Likelihood of success of hydrostatic reduction is not less in those presenting later than 48 hours. Hasnain MA, et al. showed success rate reduced to $72.8 \%$ in cases presenting in more than 48 hours duration as compared to $100 \%$ in cases presenting within 48 hours of duration. ${ }^{14}$ This fact is also demonstrated as $75 \%$ by other studies. 1,9

\section{CONCLUSION}

Our study provides a good evidence for success of hydrostatic reduction under ultrasound guidance in paediatric patients presenting with intussusception. Success rate for patients presenting presented $\leq 48$ hours was better than patients presenting presented $\geq 48$ hours.

\section{REFERENCES}

I. Caruso AM, Pane A, Scanu A, Muscas A, Garau R, Caddeo F, et al. Intussusception in children: not only surgical treatment. J Pediatr Neonat Individual Med 2017;6(I):e060I35. DOI: I0.7363/060I35.

2. Gluckman S, Karpelowsky J, Webster AC, McGee RG. Management for intussusception in children. Cochrane Database of Systematic Reviews 2017;6: CD006476. DOI: 10.1002/ |465 I858.CD006476.pub3.

3. Ogundoyin OO, Olulana DI, Lawal TA. Childhood intussusception: A prospective study of management trend in a developing country. Afr J Paediatr Surg 2015;12(4):217-20. DOI: I0.4I03/0I89-6725.|7254I.

4. Blanch AJ, Perel SB, Acworth JP. Paediatric intussusception: Epidemiology and outcome. Emerg Med Australas 2007;19(1):45-50 DOI: I0.IIII/j.I742-6723.2007. 00923.x.

5. Chen SCC, Wang JD, Hsu HY, Leong MM, Tok TS, Chin YY. Epidemiology of Childhood Intussusception and Determinants of Recurrence and Operation: Analysis of National Health Insurance Data Between 1998 and 2007 in Taiwan. Pediatr Neonatol 20 I0;5I (5):285-9I. DOI: I0.10I6/SI875-9572(I0)60055-I.

6. Jiang J, Jiang B, Parashar U, Nguyen T, Bines J, Patel MM. Childhood Intussusception: A Literature Review. PLoS ONE 2013;8(7) :e68482. DOI: 10.137I/journal. pone. 0068482

7. Ekenze S, Mgbor S. Childhood intussusception: The implications of delayed presentation. Afr J Paediatr Surg 201 I ;8(I): I5-8. DOI: 10.4103/ $0189-6725.78662$.

8. Marsicovetere $P$, Ivatury $S \mathrm{~J}$, White $B$, Holubar SD. Intestinal Intussusception: Etiology, Diagnosis, and Treatment. Clin Colon Rectal Surg 2017;30(I):30-9. DOI: I0.1055/s-0036-I593429.

9. Usang U, Inah G, Inyang A, Ekabua A. Intussusception in children: Comparison between ultrasound diagnosis and operation findings in a tropical developing country. Afr J Paediatr Surg 2013;10(2):87-90. DOI: I0.4I03/0I89-6725.II5029.

10. Bartocci M, Fabrizi G, Valente I, Manzoni C, Speca S, Bonomo L. Intussusception in childhood: role of sonography on diagnosis and treatment. JUltrasound 20 I5; 18(3): 205-I I. DOI: I0.1007/s40477-0I40II0-9.

II.Carroll AG, Kavanagh RG, Ni Leidhin C, Cullinan NM, Lavelle LP, Malone DE. Comparative Effectiveness of Imaging Modalities for the Diagnosis and Treatment of Intussusception. Acad Radiol 2017;24(5):521-9. DOI: 10.1016/ 
j.acra.2017.01.002.

12. Annigeri VMDS, Gadgade B, Halgeri $A B$, Bagalkot PS. Childhood intussusception: A 7 years prospective analysis of data in a single center. Int J Health Sci Res 2017;7(I):34-8.

13. Imran M, Ayub M, Yunas M, Aslam V, Rehman IU, Manan A. Nonoperative reduction of Intussusception in infants. J Postgrad Med Inst 2009;23(I):8I-5

14. Hasnain Z, Khalid MM, Irfan-UIHaq. Ileo-colic intussusception; is hydrostatic reduction worth considering till late? Professional Med J 20 I 4;2 I (5):864-8.

I5. Lehnert T, Sorge I, Till H, Rolle U. Intussusception in children--clinical presentation, diagnosis and management. Int J Colorectal Dis 2009;24(I 0): I | 87-92. DOI: 10.1007/s00384-009-0730-2

16. Jehangir S, John J, Rajkumar S, Mani B, Srinivasan R, Kang G. Intussusception in southern India: Comparison of retrospective analysis and active surveillance.
Vaccine 20I4;32:99-103. DOI: 10.1016/j.vaccine.2014.03.028.

17. Nasir AA, Nwosu D, Bamigbola KT, Abdur-Rahman LO, Obiora MA, Gobir AA, et al. Economics and clinical implications of delayed presentation of children with intussusceptions: minimizing healthcare cost in the context of limited resources. Egypt J Surg 20I8;37(4):600-05. DOI: I0.4I03/ ejs.ejs_II3_18.

\section{AUTHORS' CONTRIBUTIONS}

Following authors have made substantial contributions to the manuscript as under:

NU: Concept \& study design, acquisition of data, final approval of the version to be published.

MI, MIK \& MoH: Acquisition of data, drafting the manuscript, final approval of the version to be published.

IU: Analysis \& interpretation of data, drafting the manuscript, final approval of the version to be published.

MuH: Drafting the manuscript, critical review, final approval of the version to be published.

Authors agree to be accountable for all aspects of the work in ensuring that questions related to the accuracy or integrity of any part of the work are appropriately investigated and resolved.

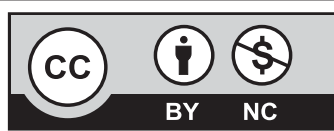

This is an Open Access article distributed under the terms of the Creative Commons Attribution-Non Commercial 2.0 Generic License.

KMUJ web address: www.kmuj.kmu.edu.pk

Email address: kmuj@kmu.edu.pk 